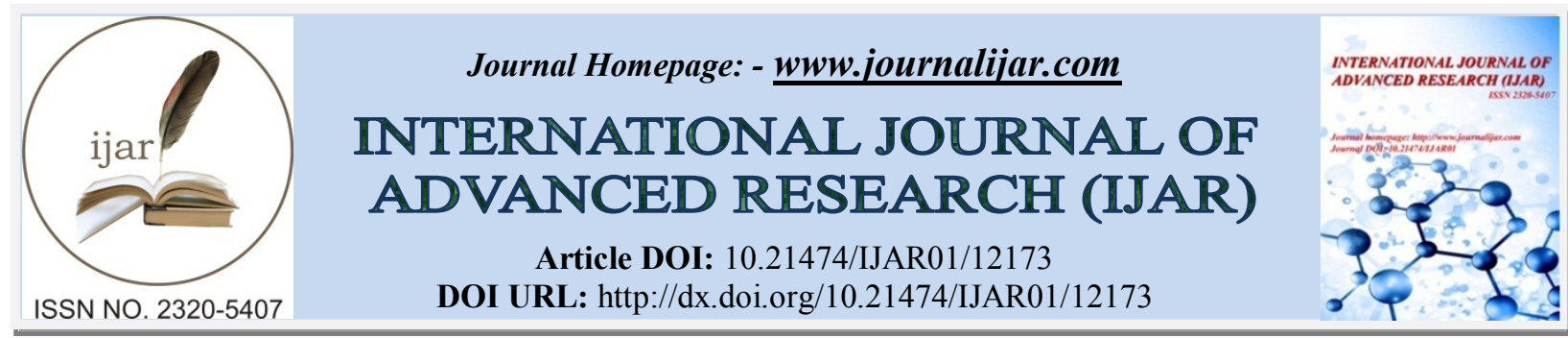

RESEARCH ARTICLE

\title{
SCREENING FOR VITAMIN D, CALCIUM AND THYROID HORMONE SERUM LEVELS IN HEALTHY ADULT LIBYAN FEMALES
}

Rehab R Walli ${ }^{1}$, Amal A Ammar ${ }^{2}$ and Rema A Abojarida ${ }^{1}$

1. Department of Biochemistry and Clinical Biochemistry, Faculty of Pharmacy, University of Tripoli, Tripoli, Libya.

2. Department of Medicinal and Pharmaceutical Chemistry, Faculty of Pharmacy, University of Tripoli, Tripoli, Libya.

\section{Manuscript Info}

Manuscript History

Received: 15 October 2020

Final Accepted: 19 November 2020

Published: December 2020

Key words:-

Vitamin D Deficiency, Blood Calcium

Levels, Thyroid Hormones

\begin{abstract}
Vitamin D deficiency is becoming endemic in many parts of the world.Several studies demonstrated a relationship between vitamin D deficiency, hypocalcemia and thyroid disorders. The purpose of this study was to examine the serum level of Vitamin D in healthy adult Libyan women and the status ofserum calcium and thyroid hormones. Serum vitamin D levels were measured in 174 healthy women who are classified in groups according to the age(Mean age $34 \pm 14$ years). Our results revealed that vitamin D deficiency is very common among Libyan adult females because the mean of vitamin D was $13.4 \pm 6.4(\mathrm{n}=174)$. Vitamin D deficiency was considered at serum levels lower than $20 \mathrm{ng} / \mathrm{ml}$.In addition, we evaluated serum level ofcalcium and Thyroidfunction hormones (TSH, T3 and T4) in only60participants from 174 who are included in this study.It has been previously shown that individuals with low vitamin D levels have low thyroid functionbut our results here indicated that serum thyroid hormones and calcium analysis were lay within the normal rang in most of the participants. Therefore, we strongly recommend the screening for Vitamin D deficiency in all adult Libyan females and encourage the advisability of increasing vitamin D intake combined with following up its serum level to avoid over dose.
\end{abstract}

Copy Right, IJAR, 2020,. All rights reserved.

\section{Introduction:-}

Vitamin D can be synthesized in adequate amounts by most mammals exposed to sufficient sunlight [1].Vitamin $\mathrm{D}$ is considered as steroidal hormone precursor.The most biologically active isoform isCholecalciferol (or vitamin D3) which is synthesized at the skin level from 7-dehydrocholesterol after exposure to ultraviolet B (UVB) radiation [2]. Vitamin D binding protein transport vitamin D to the liver, where it is converted by 25 hydroxylase enzyme to 25-hydroxyvitamin D3 (25(OH)D3), which isreflect vitamin D status [3].Vitamin D status has been proposed as a biomarker of general health proposed [4]. Different roles have been attributed to vitamin D such as the development, protection, transmission, and plasticity of the nervous system, improves insulin sensitivity, downregulates the renin-angiotensin-aldosterone system [5]. The active metabolite of vitamin $\mathrm{D}$ binds to the vitamin D receptor in the intestinal cell and stimulates the active calcium transport from the intestine to the circulation. Active calcium absorption decreases when the serum 25-hydroxyvitamin D 
$(25(\mathrm{OH}) \mathrm{D})$ concentration is $20 \mathrm{nmol} / \mathrm{L}$. Both calcium and vitamin $\mathrm{D}$ metabolites can decrease the secretion of parathyroid hormone (PTH) through the calcium sensing receptor and the vitamin D receptors respectively. This confirms that an interaction exists between calcium and vitamin D[6].Several studies observed a relationship between hypovitaminosis $\mathrm{D}$ and thyroid diseases.

There is accumulating evidence that vitamin D play a role in regulating the function of thyroid gland and Thyroid stimulating hormone (TSH) levels in the body [7]. TSH secreted from pituitary gland regulates the production of thyroid hormones thyroxine (T4) and triiodothyronine (T3). T4 and T3 play an important role in the normal growth and development of human body. Increased levels of TSH occur when the thyroid gland is unable to produce the required amount of T4 and T3, while increased levels of T4 and T3 may lead to low TSH levels. In addition, increased concentration of TSH and poor thyroid functioning have been reported in individuals with low vitamin D serum levels [8]. In the literature, the correlation between vitamin D serum level and thyroid function is not clear yet. The purpose of this study was to evaluatevitamin D and calcium status in adult females and also to find out if there is a strongassociation with thyroid function.

\section{Materials and Methods:-}

Apparently healthy women were included in this study. They were living in Tripoli region and randomly selected from the Libyan society. They were not complaining from any chronic medical diseases, no history of thyroid diseases or any chronic illness that may interfere with our results. They were not on vitamin D or calcium supplements. This study is carried out during the period from May 2018 to Sep 2018. The participants were classified into three main groups according to the age: Group I "20-30 years", Group II "31-40 years", group III “41-50 years".

Estimation of serum 25 (oh) d levels using spectrophotometric method:

Vitamin Dlevels were measured by LIAISON vitamin D chemiluminescence immunoassay (DiaSorin, Saluggia, Italy).This method is basedon that vitamin $\mathrm{D}$ forms with antimonytrichloride in chloroform a pinkcolor that can be read at 500 nmwavelength [9].Vitamin D deficiency wasdefined as a serum level ofVitamin D of less than 20 $\mathrm{ng} / \mathrm{ml}$ and levels of more than $30 \mathrm{ng} / \mathrm{ml}$ were considered normal [10].

Determination Of Serum Calcium Level Using Spectrophotometric Method:

This method is based onformation of $\mathrm{Ca}^{++}$ions violetcomplex with o-cresol-phthaleincomplex in alkaline medium. Theintensity of the color ismeasured at578nmwavelength. (CrescentDiagnostics, Cat No. CE 500). The test is linear up to Calciumvalue of $15 \mathrm{mg} / \mathrm{dl}$. Samples withhigher value should be diluted one to one with distilled water and thecalcium levels then estimatedand the results are multiplied by 2 [11].

\section{Serum Thyroid Hormone Test:}

Blood samples were taken from all participants after atleast $8 \mathrm{~h}$ of fasting. T3, Free T4, TSH were measured byCobas ECLIAs (Roche Diagnostics $\mathrm{GmbH}$, Mannheim,Germany).Reference range for normal thyroid function was considered as $(1.2-4.4 \mathrm{pg} / \mathrm{ml}$ for T3), $(0.8-2.0 \mathrm{ng} / \mathrm{dl}$ for T4) and $(0.5-5.0 \mathrm{mU} / 1$ for TSH) [12].

\section{Statistical Tests:}

Results were statistically analyzed by Sigma plot version 2 [13]. The mean and the standarddeviation (SD) for all the variables werecalculated. Unpaired student's " $t$ " test was used to compare the results of all examined groups. Thedifferences between mean values for eachtested variable have been tested. Results considered nonsignificant when $\mathrm{P}>0.05$.

\section{Results and Discussion:-}

Table 1 shows the concentrations of 25(OH)D Vitamin D in the serum of 174 females and that levels below $20 \mathrm{ng} / \mathrm{ml}$ considered as vitamin D deficiency in all age groups. Total mean of serum Vitamin D of all results obtained from 20-60 years old females equals $13.4 \pm 6.4 \mathrm{ng} / \mathrm{ml}(\mathrm{n}=174)$ with mean age of $34 \pm 14$. There is no significant difference between the groups. $100 \%$ of the females were found to be vitamin D deficient (serum $25(\mathrm{OH}) \mathrm{D} \leq 20 \mathrm{ng} / \mathrm{ml})$. 
Table 1:- Mean \pm SD of serum Vitamin D in174 womenaccording to age.

\begin{tabular}{|l|l|l|}
\hline $\begin{array}{l}\text { Sample size } \\
\text { (Number) }\end{array}$ & $\begin{array}{l}\text { Age } \\
\text { (Years) }\end{array}$ & $\begin{array}{l}\text { Vitamin D } \\
\text { (ng/ml) }\end{array}$ \\
\hline $\mathbf{N}=\mathbf{4 0}$ & $\mathbf{2 0 - 3 0}$ & $\mathbf{1 8} \pm 1.6$ \\
\hline $\mathbf{N}=\mathbf{4 2}$ & $\mathbf{3 1 - 4 0}$ & $\mathbf{1 5 . 7} \pm 1.4$ \\
\hline $\mathbf{N}=\mathbf{4 2}$ & $\mathbf{4 1 - 5 0}$ & $\mathbf{1 4 . 9} \pm 1.56$ \\
\hline $\mathbf{N}=\mathbf{5 0}$ & $\mathbf{5 1 - 6 0}$ & $\mathbf{1 0 . 9} \pm 2.13$ \\
\hline
\end{tabular}

The data of table 2 are summarized in the way to find out the status of calcium level in correlation to vitamin D status where we could measure the concentration of both vitamin D and calcium level in the same time for only 54 women (mean age, $32 \pm 8$ years), as it appears in table 2, when we calculated the mean of Vitamin D in this subgroup $(\mathrm{n}=54)$ we also got serum $25(\mathrm{OH}) \mathrm{D}$ level of $15.7 \mathrm{ng} / \mathrm{ml}$ which was also in the deficiency range.

However, the mean calcium concentration of 54 women waswithin the normal rang ( 8.5 to $10.5 \mathrm{mg} / \mathrm{dl}$ ) and there was no significant difference in meancalcium concentration between the age groups of these 54 women.

Table No 2:- Therelationship between serum concentration of vitamin D and calcium in 54 sample of 174 sample included in this study.

\begin{tabular}{|l|l|l|l|}
\hline $\begin{array}{l}\text { Sample size } \\
\text { (Number) }\end{array}$ & Age(year) & Vit. D(ng/ml) & Calcium (mg/d) \\
\hline $\mathrm{N}=20$ & $20-30$ & $13 \pm 2.7$ & $8.4 \pm 0.3$ \\
\hline $\mathrm{N}=19$ & $31-40$ & $16.5 \pm 3.2$ & $8.2 \pm 0.2$ \\
\hline $\mathrm{N}=15$ & $41-50$ & $14.1 \pm 3.5$ & $8.8 \pm 0.3$ \\
\hline
\end{tabular}

In table 3 the data represent the mean \pm SD of only 38 women from the 174 women included in this study due to some laboratory limitation. For this subgroup (38 women), we measured serum Vitamin D, TSH, T4, and T3 levels only and did not detect calcium level. The meanserum 25(OH)D level of this subgroup was $15.3 \mathrm{ng} / \mathrm{ml}$. Similarly, for participants in this subgroup they found to be vitamin D deficient. The mean of TSH concentration for in this subgroup is within the normal rang and there was no significant difference between the of mean TSH concentration of the different ages (normal range of TSHis $0.5 / 2.5 \mathrm{mU} / \mathrm{l}$ ).

Table No 3:- The relationship between mean of vitamin D andof TSH, T4, T3 concentration in 35 women.

\begin{tabular}{|l|l|l|l|l|l|}
\hline $\begin{array}{l}\text { Sample size } \\
\text { (Number) }\end{array}$ & Age (years) & Vit. D(ng/ml) & TSH(mU/l) & T3 (pg/ml) & T4(ng/ml) \\
\hline $\mathrm{N}=10$ & $20-30$ & $13 \pm 3.6$ & $1.33 \pm 0.6$ & $1.46 \pm 0.26$ & $10.04 \pm 1.8$ \\
\hline $\mathrm{N}=15$ & $31-40$ & $18.78 \pm 5$ & $2.42 \pm 0.5$ & $1.36 \pm 0.16$ & $9.06 \pm 0.8$ \\
\hline $\mathrm{N}=10$ & $41-50$ & $14.33 \pm 4$ & $1.72 \pm 0.4$ & $1.38 \pm 0.18$ & $9.37 \pm 0.9$ \\
\hline
\end{tabular}

In table 3 we collect the data in form of mean \pm SD of only 38 women from the 174 women included in this study due to some laboratory limitation. For this subgroup (38 women), we measured serum Vitamin D, TSH, $\mathrm{T} 4$, and T3 levels only and did not detect calcium level. The meanserum 25(OH)D level of this subgroup was $15.3 \mathrm{ng} / \mathrm{ml}$. Similarly, for participants in this subgroupthey found to be vitamin D deficient. The mean of TSH concentration for in this subgroup is within the normal rang and there was no significant difference between the of mean TSH concentration of the different ages (normal range of TSHis $0.5-5.0 \mathrm{mU} / 1$ ) for T3 and T4 as shown in table 3 all results are within normal range (normal range $1.2-4.4 \mathrm{pg} / \mathrm{ml}$ for T3 and $8-20 \mathrm{ng} / \mathrm{ml}$ for T4) [12].

Vitamin D is known for its primary role in bone and mineral homeostasis, and several studies reported that its deficiency is associated with various diseases such thyroid disorders, cancer, infection, and adiposity as well as osteoporosis [14]. Our results revealed decreased serum $25(\mathrm{OH})$ vit D levels in adult Libyan females. In this study, we could not find any detectable abnormality in serum calcium of the participants. The link between vitamin D deficiency and osteoporosis has been well established especially in the elderly. Vitamin D deficiency is associated with the marked suppression in intestinal Calcium absorption and the impairment of Calcium balance, which increases the risk of fractures [15].A study conducted in showed significant changes in ionized 
Calcium, but not total serum Calcium means that the physiologicallyactive form of Calcium is affected, while the overallconcentration of Calcium is still significantlyunchanged [16].

Although, our results for T3 and T4 lay within normal ranges the numbers are towards the lower value of the normal range of each. It has been previously published that there is high prevalence of hypovitaminosis $\mathrm{D}$ in patients with thyroid disorders [17] and it has been found that physiological levels of Vitamin D may affect thyroid function by modulating the immune system [18]. Moreover, it has been show that hypothyroidism patients with or without an immune base have lower levels of vitamin $\mathrm{D}(<20 \mathrm{ng} / \mathrm{mL})$ than healthy people [19]. In this context, it has been shown that low vitamin D levels increase the risk of autoimmune thyroiditis and this can also lead to abnormal TSH levels in the body [20]. Additionally, Colbay et al. showed that there is a negative correlation between TSH and vitamin D level [21]. Zhang et al. [22] indicated that the higher level of vitamin D leads to a reduction ofcirculated TSH, which are not in agreement with our resultshere but in nonimmune hypothyroidism, vitaminD didn't correlate with TSH. This shows the diverse probable role of vitamin D deficiency in the pathogenesis ofhypothyroidism. Furthermore, there is a study in 2013 performed in Saudi Arabia recorded a significant positive association between Vitamin D and calcium levels in healthy and hypothyroidism subjects [23].

\section{Conclusion:-}

Our study concluded that Vitamin D deficiency is a common health problem among Libyan women and larger multicenter studies are neededto investigate the possible measures that can be taken to solve this problem such as the impact of vitamin Dsupplementary on long-term general health status.

\section{Acknowledgement:-}

Our gratitude goes to the Biochemistry department in the faculty of pharmacy, university of Tripoli-Libya for giving us an opportunity to conduct this study.

\section{References:-}

1. Christodoulou S, Goula T, Ververidis A, Drosos G. Vitamin D, and bonedisease. Biomed Res Int. 2013;2013:396541.

2. Prietl B, Treiber G, Pieber TR, AmreinK. Vitamin D and immune function. Nutrients 2013; 5: 2502-2521.

3. Lips P. Vitamin D physiology.ProgBiophysMol Biol. 2006; 92(1):4-8

4. HolickM.F. Vitamin D deficiency. N. Engl. J. Med. 2007; 357: 266-281.

5. Kmieć P , Sworczak K. Vitamin D in thyroid disorders. Exp. Clin. Endocrinol. Diabetes. 2015; 123: 386393.

6. Bikle D. Nonclassic actions of vitamin D. J. Clin. Endocrinol. Metab. 2009; 94: 26-34.

7. Clinckspoor I, Gérard AC, Van Sande J, Many MC, Verlinden L, Bouillon R, Carmeliet G, Mathieu C, Verstuyf A, Decallonne B. The vitamin D receptor in thyroid development and function. Eur Thyroid J.2012;1(3):168-75.

8. Effraimidis G, Badenhoop K, Tijssen JGand Wiersinga WM. Vitamin D deficiencyis not associated with early stages of thyroid autoimmunity. Eur J Endocrinol.2012 Jul; 167(1):43-8.

9. Nicholas M, Robert H and Raynolds J, Spectroscopic Method for Quantitative Estimation of vitamin D, IndEng, Chem, Anal.ed.1941;13940:227-31.

10. Sadat-Ali M, AlElq A, Al-Turki H, Al-Mulhim F and Al-Ali A. Vitamin D levels in healthy men in eastern Saudi Arabia. Ann Saudi Med. 2009; 29(5):378-82.

11. Weybrew JA, Matrone G and Baxley HM.Spectrophotometric Determination of Serum Calcium. Anal. Chem. 1948;20(8):759-62

12. Kaplan MM. Clinical perspectives in the diagnosis of thyroid disease. Clin Chem.1999; 45(8):1377-83.

13. Snedecor G, Cochran W. Statistical Methods, edn. 6, Oxford \& IBH Publishing Co, New Delhi, 1967:45-83.

14. Cantorna, M.T. Vitamin D and autoimmunity: Is vitamin D status an environmental factor affecting autoimmune disease prevalence? Proc. Soc. Exp. Biol. Med. 2000; 223: 230-233.

15. Suzuki T, Yoshida H. Low bone mineral density at femoral neck is a predictor of increased mortality in elderly Japanese women. Osteoporosis Int. 2010;21:71-79.

16. Al-Hakeim HK. Serum Levels of Lipids, Calcium and Magnesium in Women with Hypothyroidism and Cardiovascular Diseases. J Lab Physicians. 2009; 1(2):49-52. 
17. Mirhosseini N, Brunel L, Muscogiuri G, Kimball S. Physiological serum 25-hydroxyvitamin D concentrations are associated with improved thyroid function-observations from a community-based program. Endocrine. 2017; 58: 563-573.

18. Adorini L, PennaG. Control of autoimmune diseases by the vitamin D endocrine system. Nat. Clin. Pract.Rheumatol. 2008; 4: 404-412.

19. Ahi S, Dehdar MR,NaserHatami N. Vitamin D deficiency in non-autoimmune hypothyroidism: a casecontrol study, BMC Endocrine Disorders. 2020; 20:41

20. Gauzzi MC, Purificato C, Donato K, Jin Y, Wang L, Daniel KC,Maghazachi AA, Belardelli F, Adorini L, GessaniS. Suppressive effect of 1alpha,25-dihydroxyvitamin D3 on type I IFN-mediated monocyte differentiation into dendritic cells: Impairment of functional activities and chemotaxis. J. Immunol. 2005; 174:270-276.

21. Colbay M, Altay M, Akturk M, Cakir N, Yetkin I, Arslan M. Vitamin D levels are ssociated with serum TSH levels but not with thyroid autoantibodies. In:13th European Congress of Endocrinology, BioScientifica. 2011;26.

22. Zhang Q, Wang Z, Sun M, Cao M, Zhu Z, Fu Q, Gao Y, Mao J, Li Y, Shi Y, Yang F. Association of high vitamin $d$ status with low circulating thyroid-stimulating hormone independent of thyroid hormone levels in middle-aged and elderly males. Int J Endocrinol. 2014;2014:631819.

23. Mackawy MA, Al-ayed MB, Al-rashidi MB. Vitamin D Deficiency and Its Association with Thyroid DiseaseInternational Journal of Health Sciences, Qassim University, Vol. 7, No. 3 (Nov 2013/ Muharram $1435 \mathrm{H})$. 